\title{
Pharmacotherapy Continuation
}

National Cancer Institute

\section{Source}

National Cancer Institute. Pharmacotherapy Continuation. NCI Thesaurus. Code

C128531.

The continuation of an existing prescription or order for a given course of treatment. 